\title{
A Balanced Literacy Initiative for One Suburban School District in the United States
}

\author{
Donita Shaw ${ }^{1}$ and Karen Hurst ${ }^{2}$ \\ ${ }^{1}$ Literacy Education, University of Kansas, Lawrence, KS 66045, USA \\ ${ }^{2}$ K-6 Curriculum and Assessment, Raymore-Peculiar School District, Peculiar, MO 64078, USA
}

Correspondence should be addressed to Donita Shaw, donita@ku.edu

Received 16 March 2012; Revised 4 June 2012; Accepted 20 June 2012

Academic Editor: Alex W. H. Chan

Copyright ( $\odot 2012$ D. Shaw and K. Hurst. This is an open access article distributed under the Creative Commons Attribution License, which permits unrestricted use, distribution, and reproduction in any medium, provided the original work is properly cited.

The purpose of this study was to investigate how the teachers employed by this suburban USA school district implemented balanced literacy instruction. The 111 teachers who taught grades K-6 completed surveys and were observed. Quantitative data from the surveys and observations were analyzed through descriptive statistics, nonparametric chi-square tests, and Pearson correlations. One open-ended survey question was analyzed qualitatively. Findings show that the majority of teachers had an acceptable understanding of balanced literacy. There were differences among teachers' instruction on literacy components and structures across grades. Weak correlations among self-reported and observed practices were found. Implications are discussed as the data are being used for research-informed improvements in the district.

\section{Introduction}

Balanced literacy is a term associated with a variety of perspectives [1]. Some view balanced literacy to be a combination of whole language and skills-based instruction [2]. Others view balanced literacy as an understanding that reading and writing develop mutually [3]. A third perspective has shown that balanced literacy is a way to provide different levels of teacher support and child control [4]. Even though "balanced literacy" may be an evasive concept without a definitive consensus among literacy researchers, all can agree it is a balance of elements. For the purposes of this paper, our balanced literacy definition mirrors that of New York City's Department of Education's research-based approach called The Comprehensive Approach to Balanced Literacy [5].

Balanced Literacy stresses the essential dimensions of reading through explicit teaching of phonics, phonemic awareness, fluency and expressiveness, vocabulary, and comprehension. Daily readalouds, independent reading time, reading workshop, writing workshop, and systematic word study instruction are key features of the approach. Teachers demonstrate the habits and strategies of effective reading and writing through a variety of structures: read-aloud, guided reading, shared reading, interactive writing, and minilessons in reading and writing. By coaching students in individual or small-group conferences, teachers allow students to successfully and independently apply those strategies to their own reading and writing.

The goal of one Midwestern United States school district is to make literacy accessible to all students by expanding teachers' knowledge and participation in balanced literacy instruction. The district believes balanced literacy instruction is important because it responds to students' needs [6$8]$ and leads to high academic achievement $[9,10]$. The district maintains to follow a balanced literacy philosophy, yet with minimal explicit professional training to support teacher understanding. The purpose of this study was to investigate how the teachers employed by this district implemented balanced literacy instruction for research-informed improvements in education. We explored three questions.

(1) How did the teachers define balanced literacy?

(2) What literacy components and literacy structures did the teachers emphasize? Were there differences across grade levels? 
(3) How did the teachers self-report their implementation of literacy components and structures? How did their perceived data compare to observed data?

\section{Literature Review}

The underpinning for a student's success in today's society is the development as a strong reader and writer. Throughout the years, there have been different philosophies about how children learn to read. The whole language movement made its debut in America in the late 1980s. This philosophy of learning advocated that students learn to read and write in a manner similar to how they learn to speak [11], namely, through holistic, rich authentic experiences rather than the teaching of skills $[11,12]$. Whole language is most generally considered a top-down reading model [13] which suggests that readers predominantly rely on prior knowledge and emphasize meaning making. In contrast is the skills-based phonics approach [14]. This approach's initial emphasis is on the direct teaching of isolated letter-sound correspondences through analytic or synthetic methods. Skills-based or phonic methods are often considered a bottom-up model [14]. Bottom-up models envision the reading process as one during which learners ultimately acquire meaning by first focusing on the graphemes and associating their phonemes, then by combining graphemes-phonemes into words which string together to create sentences [15]. A balanced reading program emphasizes an interactive model that proposes that readers use both top-down and bottom-up processes [16]. The interactive model suggests that students know and implement the alphabetic principle and bring their prior knowledge to bear while reading. Research by Snow et al. [2] supports the idea that the successful teaching of reading requires skill instruction, including phonics and phonemics, in conjunction with stimulating reading and writing experiences. Also recommended is the explicit teaching of phonics and comprehension as well as immersion in literature $[17,18]$. In 2000, the National Reading Panel disseminated a report that identified five skill areas which are essential for students' development as readers. These include phonemic awareness, phonics, fluency, vocabulary, and text comprehension. Today, balanced literacy is often characterized in a more comprehensive and complex way than literacy components. Balanced literacy is a philosophical orientation that envisions that reading and writing achievement are developed through instruction and support in multiple environments using various approaches that differ by level of teacher support and child control [4]. Balanced literacy in the classroom includes the use of such varied structures such as read-aloud, guided reading/writing, shared reading/writing, and independent reading/writing [4]. A successful balanced literacy program, it is argued, must combine teacherdirected instruction (including teacher modeling of skills, strategies, and processes) and student-centered activities (student choice of reading materials) [1, 2, 19, 20].

Districts across the country are incorporating a balanced model within their literacy programs. A report by Ivey et al. [21] acknowledged that implementation of a balanced model varies district to district, with each neither right nor wrong. Factors of classroom management and teacherdecision making can influence the level of implementation. Marinek and Henk [22, page 168] stated that "social, historical, economic, psychological, philosophical, demographic, and political factors all set the stage for different literacy outcomes." Such factors are important to understand when analyzing the district's implementation, remembering that instituting a balanced instructional model may not be an exact science. Iversen [23] describes the components as "intersecting and overlapping" and dynamic because they are not discrete or fixed and offer the teacher flexibility and the opportunity to use professional knowledge. Further, a balanced approach may need to evolve over time based on ever-changing student needs [22]. "A balanced approach allows a faculty to agree on a small core of principles about teaching and learning and a small core of curriculum around which each teacher can individualize" [24, page 15]. The concept of balanced literacy is a dynamic model.

Frey et al. [7] investigated one high-poverty urban school district's attempt to create balanced literacy instruction in their schools. Data were triangulated from classroom observations, teacher surveys, student interviews, and inventories of school and classroom environments. Frey and colleagues discovered physical elements (e.g., classroom library, literacy centers, and displays) were present. They found teachers attempted to allocate instructional time and implement the balanced components. However, independent reading and writing in the form of seatwork was more frequently observed than modeling or direct instruction, which was of concern especially for the students who struggled with reading and writing.

A study by Bitter et al. [25] analyzed the instruction within San Diego classrooms to measure the consistency of best practice determined by the district and whether the balanced instructional practices were associated with an increase in reading achievement. Teacher interviews and observations along with student achievement data were collected from nine poverty schools over two years. The research concluded that a balanced approach which includes higherlevel questioning, student engagement through responsible conversation, and scaffolding of instruction can yield improvements in student achievement.

Previous research has shown that teachers often lack a definition for balanced literacy [26]. When teachers lack understanding of balanced literacy instruction, the result may be a distorted or superficial view [24]; teachers cannot intelligently implement, modify, or reject approaches, strategies, and viewpoints. The broader the teachers' understanding is, the more complete their repertoire will be and their success at teaching balanced literacy. Willows [27] stated that knowing the literacy components is not enough. Teachers must have a thorough understanding of the rationale for implementing specific instructional components. The same is true for structures. Knowledge about structures is insufficient. When teachers possess deeper understanding, they will have a better chance of ensuring their students will become strong readers and writers. To support this finding, Pressley et al. simply stated that "excellent literacy teachers do it all" [28, page 11]. 


\section{Methodology}

3.1. Participants. Meadow View (pseudonym) School District is located in a suburb of a Midwest metropolitan city in the United States. The student population is comprised of Caucasian (87\%), African American (9\%), Hispanic (2.4\%), Asian (1.1\%), and Native American (less than 1\%). The district has six elementary schools, which serve kindergartenfourth grade, and two intermediate schools, which serve students in grades five and six. The elementary schools have the typical classroom setting where one teacher instructs students in multiple subjects. In contrast, the intermediate school faculty instruct a specialty area. For this study, all elementary $(K-4)$ teachers and only the communication arts fifth and sixth grade intermediate teachers were included. A total of 111 teachers had an average of 9.5 years of experience. Approximately 65\% held master degrees, $24 \%$ bachelor degrees, and $11 \%$ held a specialist degree. The primary ethnicity of teachers was Caucasian (99\%).

3.2. Data Collection and Sources. We collected data from classroom observations and teacher surveys. The first author, a literacy researcher, met with the second author, a district leader, to discuss and revise the observation and survey instruments obtained from Frey et al. [7]. Next, the district's literacy taskforce, comprised of a reading specialist from each school, literacy coaches (whom each serve two buildings), and principals, reviewed the research instruments and made suggestions, which the first author revised. Finally, the first author met with the literacy taskforce to discuss and revise the instruments one final time. At this meeting the procedures for data collection were discussed.

3.3. Classroom Observations. All kindergarten-fourth grade and communication arts fifth-sixth grade teachers were observed during one school day by the first author/researcher. District administrators and principals coordinated dates with the researcher for the school visits, but teachers were not told the specific day of the observations so they could not purposefully change their instruction. During one full day in each school, the first author randomly sampled each teacher's classroom as frequently as possible, on average five times per classroom, during literacy instruction. The activities and instruction were documented in written form. For example, in Classroom A, the teacher was conducting a guided reading group with five children, focusing on comprehension (the teacher asking questions), while the remaining students were independently reading or doing word work/phonics at their seats. In Classroom B, the teacher was conducting a whole class comprehension lesson by reading aloud a picture book and pausing occasionally for the students to make connections. Then returning to Classroom A, the teacher was reading aloud to the students for pleasure. Later in Classroom B, the teacher was conducting writing workshop: she used shared writing as her minilesson, followed by students independently writing while the teacher conferred with students. This type of documentation occurred throughout the day.
At the end of each school visit, the first author read through the qualitative notes and inserted the information into a checklist adapted from Frey et al., 2005 [7]. One checklist was prepared for each grade level at each school and included the entire day's observations across teachers $(N=3$ or $N=4)$ for frequency of occurrence. For example, in Classroom A samples, the following items were marked on the checklist: (1) components: phonics and comprehension, (2) structures: guided reading, independent reading and read aloud. Classroom B's checklist for the two samples had the following markings: (1) components: comprehension, mini lesson and writing process, (2) structures: read aloud, shared writing, and independent writing.

The question of the degree of confidence that one can place on a small sample of teacher behavior as representative of general classroom practice arises in studies like this one. Stallings and Frieberg [29], Ayers [30], and more recently Tollefson et al. [31] and Frey et al. [7] demonstrated that teachers show a high level of consistency in their classroom interactions over time. This is especially true for lowinference behaviors such as the use of direct observations of concrete behaviors in this study.

3.4. Teacher Surveys. A three-page survey collected teachers' self-reported data that contained Likert scale responses and open-ended questions. The Likert-scale responses asked teachers to rate their frequency (1-6 scale) for which they implement literacy structures and instructional components. A score of 6 indicated they implemented the structure/component every day, 4 was weekly implementation, 2 was monthly implementation, and 1 was recorded if they rarely/never implemented each structure/component. The open-ended questions solicited teachers' definition of balanced literacy, their practices on student achievement data analysis, collaboration with the literacy coach and reading interventionist, involvement with a balanced literacy group, literacy teaching strategies, implementation of reading and writing notebooks, and use of resources and professional library. For the purposes of this paper, only the first open response is included in the results.

Surveys were printed on paper and teachers completed a written copy before the first author completed observations. The teachers placed the completed survey in a sealed envelope, and then that envelope was put into a second envelope, for a double-blind process. On the outside (second) envelope they wrote their name so the principal could account for completed surveys. The outside envelope was taken off by the principal's secretary and destroyed before giving the inner (anonymous) envelope to the first researcher. Surveys were distributed to 111 teachers and a total of 105 were returned for a $95 \%$ response rate.

3.5. Data Analysis. The observational data and teacher Likert scale responses were entered into SPSS by row (independent variable grade/school) and column (dependent variable component or structure). Descriptive statistics were used to determine demographics and report means and frequencies. Next, we conducted nonparametric 
TABLE 1: Frequency of observed reading components.

\begin{tabular}{lccccccc}
\hline & $K$ & 1 & 2 & 3 & 4 & 5 \& 6 & Average \\
\hline Phonemic awareness & $18.93 \%$ & $5.56 \%$ & $0.00 \%$ & $0.00 \%$ & $0.0 \%$ & $0.00 \%$ & $4.59 \%$ \\
Phonics/word study & $71.49 \%$ & $60.20 \%$ & $47.14 \%$ & $28.70 \%$ & $0.0 \%$ & $37.22 \%$ & $41.24 \%$ \\
Fluency & $3.33 \%$ & $14.05 \%$ & $10.18 \%$ & $9.35 \%$ & $0.0 \%$ & $0.00 \%$ & $6.92 \%$ \\
Vocabulary & $0.00 \%$ & $2.78 \%$ & $5.42 \%$ & $1.85 \%$ & $0.0 \%$ & $15.00 \%$ & $2.82 \%$ \\
Comprehension & $6.25 \%$ & $17.42 \%$ & $37.26 \%$ & $60.09 \%$ & $100.0 \%$ & $47.78 \%$ & $41.30 \%$ \\
\hline
\end{tabular}

chi-square tests to examine relationships between items. Kruskal-Wallis evaluates the mean rank of the dependent variable (e.g., components or structures) to determine if it is the same across all levels of a factor (e.g., grade levels). We used Kruskal-Wallis to determine across grades whether there were significant differences on the usage of structures and components. Finally, we ran Pearson correlations to determine the relationship of observed behavior to reported behavior.

The first open-ended survey statement, "Please write in your own words your definition of balanced literacy" was typed for all the teachers. The first author went through the data using qualitative analysis: read all the teachers' responses multiple times, identified ratings or categories, and then look for the frequency of those categories [32]. Ratings (exemplary, acceptable, and inadequate) of definitions were developed from the generalizations.

An outside consultant read through the quantitative and qualitative data creating checklists for the components/structures and provided ratings for the definitions similar to the first author. Across the first author and consultant, there was $>85 \%$ reliability or agreement.

\section{Results}

The results will be presented by guiding questions.

How did teachers define balanced literacy?

To answer this question, we qualitatively looked for categories in their answers. Most of the teachers $(84 \%)$ communicated a definition of balanced literacy that was acceptable, but not encompassing. For example, one teacher said "Balanced literacy is a program that has guided reading, independent reading, shared reading, word work and writing." This shows that the teacher had acceptable understanding about balanced literacy, but s/he did not totally understand that it is a framework rather than a program and neither did the teacher communicate all the structures and the components. We found most teachers wrote definitions that focused on structures (e.g., guided reading and independent reading) rather than literacy components (e.g., phonics, vocabulary, and comprehension). About $10 \%$ of the teachers did not seem to understand balanced literacy and thus gave an inadequate definition. One teacher wrote "Where all students learn to read and write effectively." While we hope this is the goal of balanced literacy, a lot of information is missing to indicate complete understanding. In contrast, less than $6 \%$ of the sample had exemplary definitions. An example is "Students are engaged in classroom activities where they interactively learn to read and write.
Activities are based on literacy areas including phonemic awareness, phonics, fluency, vocabulary, comprehension and writing. Components of balanced literacy include: reading aloud, shared reading, reading workshop, shared writing, interactive writing, writing workshop."

What literacy components and structures did the teachers emphasize? Were there differences across grade levels?

To answer what teachers emphasized, we tabulated the frequency of observed use of components and structures. We used a Kruskal-Wallis one-way analysis of variance to test whether there were differences across grade levels.

Table 1 shows the frequency of use for each reading component as a percentage across grade levels. The results show the components in relation to each other and which components dominated the instruction. As expected, kindergarten teachers used more phonemic awareness activities than teachers in other grades. Phonics gradually tapered off by third grade. In fifth-sixth grade phonics/word study instruction focused on spelling and structural analysis. Interestingly, all fourth grade observations documented comprehension instruction and no other reading skill instruction was seen. Comprehension strategy instruction was observed in almost all classrooms, but vocabulary and fluency instruction were limited.

To assess whether there were differences on how teachers emphasized instructional components across the grade levels, we conducted Kruskal-Wallis analyses of variance. There was a significant difference among grade levels on phonics, $\chi^{2}(5)=18.70, P=0.002$. The lower grades had much higher mean ranks than the intermediate grades. A significant difference was also found on comprehension $\chi^{2}(5)=12.25$, $P=0.031$.

Table 2 documents the frequency of observed writing components across grade levels. Minilessons, writing process, student share, and grammar were instructed in all classrooms. Handwriting received less attention, specifically in second, fourth, fifth and sixth grades. To assess whether there were differences on the writing components across the grade levels we conducted Kruskal-Wallis analyses of variance. There was a significant difference among grades on the writing process, $\chi^{2}(5)=11.28, P=0.046$.

Table 3 shows the percentages for classroom structures of reading and writing across grade levels. The findings show read alouds were much more common in kindergarten than in any other grade. Shared reading was never observed in any of the classrooms. Guided reading or small group instruction was used by most teachers in first grade, but no teachers in kindergarten or fifth, and sixth grade. Modeled writing was not observed and shared writing was minimally observed. It 
TABLE 2: Frequency of observed writing components.

\begin{tabular}{lccccccc}
\hline & $K$ & 1 & 2 & 3 & 4 & 5 \& 6 & Average \\
\hline Minilesson & $40.00 \%$ & $28.50 \%$ & $28.00 \%$ & $33.33 \%$ & $33.33 \%$ & $12.00 \%$ & $29.19 \%$ \\
Write process & $10.00 \%$ & $35.70 \%$ & $44.00 \%$ & $33.33 \%$ & $33.33 \%$ & $24.00 \%$ & $30.06 \%$ \\
Student share & $10.00 \%$ & $7.14 \%$ & $16.00 \%$ & $5.55 \%$ & $16.67 \%$ & $16.00 \%$ & $11.89 \%$ \\
Handwriting & $20.00 \%$ & $14.28 \%$ & $0 \%$ & $5.55 \%$ & $0 \%$ & $0 \%$ & $6.64 \%$ \\
Grammar & $20.00 \%$ & $14.28 \%$ & $12.00 \%$ & $22.22 \%$ & $16.67 \%$ & $48.00 \%$ & $22.20 \%$ \\
\hline
\end{tabular}

Table 3: Frequency of observed literacy structures.

\begin{tabular}{lccccccc}
\hline & $K$ & 1 & 2 & 3 & 4 & 5 A 6 & Average \\
\hline Read aloud & $52.17 \%$ & $4.34 \%$ & $9.09 \%$ & $11.76 \%$ & $10.71 \%$ & $21.43 \%$ & $18.25 \%$ \\
Share reading & $0.00 \%$ & $0.00 \%$ & $0.00 \%$ & $0.00 \%$ & $0.00 \%$ & $0.00 \%$ & $0.00 \%$ \\
Guide reading & $0.00 \%$ & $43.47 \%$ & $34.09 \%$ & $35.29 \%$ & $46.43 \%$ & $0.00 \%$ & $26.55 \%$ \\
Ind. reading & $4.34 \%$ & $36.96 \%$ & $29.55 \%$ & $26.47 \%$ & $21.43 \%$ & $28.57 \%$ & $24.55 \%$ \\
Model writing & $0.00 \%$ & $0.00 \%$ & $0.00 \%$ & $0.00 \%$ & $0.00 \%$ & $0.00 \%$ & $0.00 \%$ \\
Shared writing & $4.34 \%$ & $2.17 \%$ & $0.00 \%$ & $0.00 \%$ & $0.00 \%$ & $0.00 \%$ & $1.09 \%$ \\
Ind. writing & $39.13 \%$ & $13.04 \%$ & $27.27 \%$ & $26.47 \%$ & $21.43 \%$ & $50.00 \%$ & $29.56 \%$ \\
\hline
\end{tabular}

was much more common to see students independently writing. To assess whether there were differences on the reading and writing structures across the grade levels, we conducted Kruskal-Wallis analyses of variance. There was a significant difference among grades on guided reading, $\chi^{2}(5)=$ $11.53, P=0.042$. No significant differences across grade levels for writing structures were found.

How did the teachers self-report their implementation of instructional components and structures? How did their perceived data compare to observed data?

The teachers were given opportunity to document how frequently they instruct reading and writing components and structures. The results in Table 4 are for teachers across all grade levels. The data show that the suburban teachers' responses were fairly consistent in their instruction of all literacy components and structures. The fact that $10 \%$ of the teachers rarely or never teach phonemic awareness is a developmentally acceptable practice. About $10 \%$ said they never teach the writing process and 19\% documented their lack of handwriting instruction. About $13 \%$ of the teachers said they rarely implement guided reading and shared writing.

To answer the second research question, we conducted correlations between teachers reported data and observed data. Statistics for the category of reading components were run and the only significant correlation was between selfreported and observed phonics, $r(32)=0.46, P=0.008$. No self-reported/observed writing components were significant. Next, we looked at writing structures and found none to be significant, but among reading structures we found guided reading to be significant, $r(32)=0.38, P=0.034$. Most of the correlations, except phonics, were in the weak range.

\section{Discussion}

In this paper, we investigated teachers' knowledge of balanced literacy and their practices in order for the district to make research-informed improvements. Within the past two years, the teachers in this district have been encouraged to implement balanced literacy instruction with minimal professional development.

We began by analyzing their definitions. Previous research stated that teachers often do not have a definition for balanced literacy [26] and a distorted or superficial view may result in teachers' inability to implement or modify an approach or philosophy. We found that most of the teachers possessed acceptable knowledge of balanced literacy, although some professional development could be provided to enable teachers to more fully understand this framework. Any district initiative takes time for teachers' knowledge and buy-in to increase so district leaders should be encouraged that the fundamental aspects of balanced literacy are known by the majority of their teachers.

Balanced literacy is based on research. Even though numerous publications promote balanced literacy in general $[1,33]$ and specifically advocate teaching the components $[34,35]$ and using the structures [4], minimal research is available on these components and structures in practice. The amount of time invested in literacy instruction is the "most important alterable determinant" for student achievement [35]. Two hours of literacy instruction is quite common in Midwest USA schools; the Meadow View District requires that amount of instructional literacy time in their classrooms. Yet, we know little about what components teachers emphasize the most and what structures they most frequently use during the literacy instruction. We found some of the observational data surprising and informative showing how the components and structures are in relationship to each other and which ones dominate the instruction of teachers in this particular district. For example, strengths were clearly seen across schools and grades in the areas of comprehension and writing. In comparison to the San Diego district [25], a focus on these two areas specifically contributed to increased student achievement. Teaching 
TABLE 4: Teachers' self-reported instruction.

\begin{tabular}{|c|c|c|c|c|c|c|}
\hline Every day & A few days a week & Weekly & A few days a month & Monthly & Rarely or never & \\
\hline Phonemic awareness & $42.7 \%$ & $24.7 \%$ & $9.5 \%$ & $11.5 \%$ & $1.4 \%$ & $10.2 \%$ \\
\hline Phonics & $47.2 \%$ & $20.0 \%$ & $13.5 \%$ & $13.9 \%$ & $1.5 \%$ & $3.9 \%$ \\
\hline Vocabulary & $27.8 \%$ & $48.5 \%$ & $18.1 \%$ & $5.6 \%$ & $0.0 \%$ & $0.0 \%$ \\
\hline Comprehension & $68.9 \%$ & $23.6 \%$ & $4.9 \%$ & $1.8 \%$ & $0.0 \%$ & $0.7 \%$ \\
\hline Fluency & $49.7 \%$ & $33.5 \%$ & $9.4 \%$ & $3.9 \%$ & $1.4 \%$ & $2.1 \%$ \\
\hline Grammar & $36.1 \%$ & $28.7 \%$ & $23.1 \%$ & $6.2 \%$ & $4.6 \%$ & $1.3 \%$ \\
\hline Minilesson & $33.2 \%$ & $46.3 \%$ & $10.8 \%$ & $5.1 \%$ & $0.0 \%$ & $4.7 \%$ \\
\hline Write process & $29.4 \%$ & $31.9 \%$ & $17.4 \%$ & $7.9 \%$ & $3.3 \%$ & $10.2 \%$ \\
\hline Student Share & $20.2 \%$ & $28.3 \%$ & $38.3 \%$ & $9.8 \%$ & $2.8 \%$ & $0.6 \%$ \\
\hline Handwriting & $28.9 \%$ & $27.9 \%$ & $11.9 \%$ & $12.1 \%$ & $0.0 \%$ & $19.1 \%$ \\
\hline Ind. reading & $81.2 \%$ & $15.0 \%$ & $1.5 \%$ & $0.8 \%$ & $0.0 \%$ & $1.4 \%$ \\
\hline Guided reading & $50.7 \%$ & $23.9 \%$ & $8.5 \%$ & $1.6 \%$ & $1.6 \%$ & $13.8 \%$ \\
\hline Shared reading & $39.9 \%$ & $41.5 \%$ & $12.3 \%$ & $1.5 \%$ & $1.5 \%$ & $3.3 \%$ \\
\hline Read aloud & $66.8 \%$ & $17.9 \%$ & $9.7 \%$ & $0.0 \%$ & $1.9 \%$ & $3.7 \%$ \\
\hline Model writing & $22.2 \%$ & $41.1 \%$ & $21.5 \%$ & $11.1 \%$ & $0.0 \%$ & $4.0 \%$ \\
\hline Shared writing & $5.9 \%$ & $46.5 \%$ & $25.2 \%$ & $8.0 \%$ & $0.6 \%$ & $13.7 \%$ \\
\hline Ind. writing & $56.6 \%$ & $21.4 \%$ & $17.9 \%$ & $0.0 \%$ & $1.4 \%$ & $2.7 \%$ \\
\hline
\end{tabular}

students how, when, and why to apply comprehension strategies is important for developing effective readers [36]. Likewise, writing is essential to communication and learning, therefore teachers have a responsibility to teach writing rather than assign writing [37]. Fortunately, a great amount of emphasis was devoted to these two aspects by Meadow View District.

Another finding from Meadow View District was the limited emphasis on fluency and vocabulary instruction. Interestingly, Bitter et al. [25] also found limited instruction in phonics, vocabulary, and word study. According to Shanahan [35], the four core areas of word knowledge (phonemic awareness and phonics), comprehension (vocabulary), fluency, and writing are equally important. Further, the National Reading Panel [34] showed that fluency and vocabulary, two of five core reading foci, are instrumental to students' literacy development. We should mention a limitation of this study is that observations were conducted on one day in each school, so it is possible that more emphasis was devoted to these areas on another day. That said finding cannot be dismissed because these components are too important. Rasinski and Samuels [38] stated that fluency is important not only in the primary grades but through intermediate grades all the way to secondary school. Vocabulary has repeatedly been found to be a strong predictor of comprehension [39].

The gradual release model [36] provides four levels of support to give the students progressive responsibility for learning a concept or strategy. The gradual release of responsibility begins with teacher modeling, then coaching through shared and guided practice, followed by giving students control with independent practice. The structures of the balanced literacy framework are a flexible organizational tool that helps teachers engage students in a variety of experiences [4]. All four structures are fundamental to effective instruction and student achievement [36]. Within this framework, we found Meadow View teachers minimally provided some portions of the gradual release model, specifically shared reading and writing and modeled writing. Interestingly, teachers in a neighboring metropolitan district also spent the greatest proportion of their time on reading aloud and independent writing [7]. Frey and colleagues suggested one possible reason is that the teachers used independent reading and writing as a classroom management technique and a second reason may be teachers prefer increased productivity and creativity associated with independent tasks. We agree that these two reasons are possibilities for why Meadow View teachers may have incorporated more independent work. However, we also propose that teachers were not familiar with the importance of the shared reading and writing structures and how to integrate them into their lessons. Since there was limited professional development of balanced literacy, teachers incorporated the aspects they knew. Even though teachers' definitions focused more on structures than components, limited knowledge on all the structures may have impacted their understanding and thus practice of the four levels of support. Other factors such as social, historical, demographic, philosophical, or political were not solicited and would be an ideal question for future research.

Classroom teachers self-reported that they incorporate most aspects of balanced literacy components on a regular basis. According to the teachers, handwriting, writing process, and phonemic awareness were the least commonly taught components. Of these, phonemic awareness is a beginning reader skill, so some teachers may not incorporate phonemic awareness in their instruction. However, handwriting and the writing process should be instructed daily across all grades. Across structures and components, we found teachers tended to rate themselves higher than the observations showed.

As with any research, this study had its limitations including length of time spent in each classroom, use of 
surveys rather than focus groups or interviews, and lack of measurement of teacher quality. A future study should not only document what a teacher is doing but also measure the quality of teaching that component or using that structure. Future research can also include teacher interviews or focus groups. A focus of interviews could be on "why" teachers make these decisions and what factors contribute to their instruction. Teacher rationale can impact educational policy and boost level of program implementation. If funding and greater human resources are available, spending more time in classrooms should be a priority.

\section{Educational Importance}

Numerous manuscripts have researched effective schools $[8$, 40] and classrooms [41]. These studies have been helpful in identifying effective classroom characteristics such as a literate environment, explicit teaching, variety of reading materials, motivation, and accountability. Yet these articles do not address the components and structures of balanced literacy. Therefore, our research can enrich the field in three ways: through the literature on teacher education, educational policy making, and balanced literacy practice.

6.1. Teacher Education. Teacher knowledge has been shown to be more important than instructional method or socioeconomic status with regards to effective teaching [42]. Good instructional practice is complex and necessitates time to learn. It requires much hard work on the part of teachers and extensive knowledge of many areas in literacy [1].

Following, we provide an example of what the literature says about teacher knowledge on one component: alphabetics (i.e., phonemic awareness and phonics). Research shows that both beginning teachers [43] and practicing teachers $[44,45]$ who are directly responsible for teaching children to read do not possess adequate alphabetical knowledge. There is a mismatch between primary grade teachers' selfperceptions of their competency and their actual knowledge $[44,46,47]$. Cunningham et al. [46, page 162] stated "We have much work to do in professional development in the domains of phonological awareness and phonics...It is of concern because it is critical that people know what they do not know."

Similar research could be included for the other components and the gradual release model (structure). Haynes [48] stated that teachers are not prepared to teach literacy and universities underestimate the literacy knowledge and training preservice teachers need. If this is the case, then school districts are responsible for providing appropriate, purposeful, and meaningful professional development.

That said, providing professional development is not enough. Schools must monitor how the curriculum is taught, how the materials are used to support the curriculum, and data should be collected to show students are learning [49]. Monitoring the implementation of curriculum contributes to improvement. According to the research, there are several reasons for monitoring curriculum: efficiency of time and money, consistent development for student success, teacher alertness and accountability, and the principal will become more visible and involved with curriculum which contributes to school improvement [50].

One consideration for higher educational institutions, state boards of education, and school districts is to understand Zeichner and Gore's [51] theory of teacher socialization. This theory holds that an individual becomes a participating member in the society of teachers through a process that is influenced by pretraining experiences as a pupil, formal preservice teacher education, and inservice years of teaching. Teachers become socialized into the profession through practice. Meaning is derived through social interaction between persons and modified through a largely internal process of interpretation. Becoming a professional teacher is an interactive and interpretive process between the meaning making of a teacher in relation to the context of his/her professional development program and the context of his/her actual practice. The theory of teacher socialization promotes coherence between thought and action.

6.2. Policy Making. It is important for effective infrastructures to be developed that support teaching and assessment. National or state policy makers should put forth effort to create a comprehensive plan that addresses all primary and secondary students' needs. In the USA, state boards of education could collaborate with higher educational institutions, school districts, schools, and teachers to craft a literacy plan that ensures training and support for teachers [48]. The plan needs to have a vision for aligning educational systems and invest in teachers. Teachers are at the center of instruction, so policy makers should see that district leaders provide teachers with opportunities to increase their knowledge, improve their practice through feedback, and receive ongoing training and support. One possibility is to develop tools that can be used for collecting data on teaching rather than simply assessing student data. In this study, we adapted previously-developed instruments [7] that the district school principals continue to use as they walk through their teachers' classrooms. The principals and district administrators are able to continue teacher data collection for their accountability and to inform professional development. Haynes [48] has published a document that outlines how to move from state policy to impacting classroom practices. She provides action steps that must be taken at all levels including state, district, school, and classroom in order to positively impact teachers' instructional practices and improve students' literacy skills. Haynes organizes her action plan around five areas: planning, quality of teaching, use of data, instructional infrastructure, and accountability. We recommend policy makers visit her publication (see references) and use this helpful document to make positive changes.

6.3. Balanced Literacy. We know a lot about literacy components [34] and structures [4], independently, but we have very little information about how these look in balanced literacy classrooms. Very few studies [7, 25] provide situated 
examples of balanced literacy in districts. Authors such as Pressley et al. $[8,40]$ have called for more examples of balanced literacy in action.

This study contributes to the field by providing information on what components teachers emphasize and the structures they use during their 2-hour literacy block in one school district in the United States. Frey et al. [7, page 279] said "The literature has not established an optimal amount of time to spend on literacy activities or the best balance of activities for balanced literacy." Even though the teachers in this study had strengths and weaknesses, the data show reality in classrooms. It is our hope that after several manuscripts have published information about teachers' practices in balanced literacy that Frey et al.s [7] statement about identifying the best balance of components and structures can be answered.

The major implication of these findings is that teachers attempt to put into practice what they know about balanced literacy. We discussed the importance of knowledge in the section of teacher education. Based on a random sample, the observational data confirmed that direct instruction of skills and strategies and student-centered reading and writing activities [2] was taking place in Meadow View Schools. Professional development had been given in the components of comprehension and writing, and these were evident in many classrooms. Bitter et al. [25] also found that teachers' practices aligned with schools' instructional focus. The district is currently using the data to develop future professional development specifically in the areas of shared reading and writing as well as vocabulary and fluency during this school year.

\section{Conclusion}

With increased emphasis on literacy in our schools, educators should evaluate the processes and outcomes of schoolwide approaches to teach reading. In sum, the teachers in this district have acceptable knowledge about balanced literacy and were implementing balanced literacy instruction, although there was unequal distribution of literacy components and structures. In this paper, we attempted to erase confusion of a term by providing a clear definition of balanced literacy [26]. Through observations, we focused on literacy components [34] and gradual release model structures [36] and the integrity of the teachers' implementation of these. We adapted previously-developed instruments [7] that school principals continue to use as they walk through their teachers' classrooms for their own data and accountability. Through surveys and observations, we provided the field with specific information about processes that advance literacy research. This careful examination can support school districts as they attempt data-based school reform.

\section{References}

[1] P. A. Freppon and K. L. Dahl, "Balanced instruction: insights and considerations," Reading Research Quarterly, vol. 33, no. 2, pp. 240-251, 1998.
[2] C. E. Snow, M. S. Burns, and P. Griffin, Preventing Reading Difficulties in Young Children, National Academy, Washington, DC, USA, 1998.

[3] J. Fitzgerald and T. Shanahan, "Reading and writing relations and their development," Educational Psychologist, vol. 35, no. 1, pp. 39-50, 2000.

[4] I. C. Fountas and G. S. Pinnell, Guided Reading: Good First Teaching for All Children, Heinemann, Portsmouth, NH, USA, 1996.

[5] New York City Department of Education, 2011, http:// schools.nyc.gov/academics/EnglishLanguageArts.

[6] J. F. Alamasi, Teaching Strategic Processes in Reading, Guilford, New York, NY, USA, 2003.

[7] B. B. Frey, S. W. Lee, N. Tollefson, L. Pass, and D. Massengill, "Balanced literacy in an urban school district," The Journal of Educational Research, vol. 98, no. 5, pp. 272-280, 2005.

[8] M. Pressley, L. Mohan, L. M. Raphael, and L. Fingeret, "How does Bennett Woods Elementary School produce such high reading and writing achievement?" Journal of Educational Psychology, vol. 99, no. 2, pp. 221-240, 2007.

[9] J. Brown and P. Fisher, "Balanced literacy: one middle school's experience," Principal Leadership, vol. 7, no. 1, pp. 38-40, 2006.

[10] B. M. Taylor, P. D. Pearson, D. S. Peterson, and M. C. Rodriguez, "Reading growth in high-poverty classrooms: the influence of teacher practices that encourage cognitive engagement in literacy learning," The Elementary School Journal, vol. 104, no. 1, pp. 3-28, 2003.

[11] K. Goodman, "Whole language research: foundations and development," Elementary School Journal, vol. 90, no. 2, pp. 207-221, 1989.

[12] D. J. Watson, "Defining and describing whole language," Elementary School Journal, vol. 90, no. 2, pp. 128-141, 1989.

[13] F. Smith, Reading Without Nonsense, Teachers College, New York, NY, USA, 2nd edition, 1985.

[14] J. L. Vacca, R. T. Vacca, M. K. Gove, L. Burkey, L. A. Lenhart, and C. McKeon, Reading and Learning to Read, Allyn \& Bacon, Boston, Mass, USA, 2003.

[15] P. B. Gough, "One second of reading," in Theoretical Models and Processes of Reading, H. Singer and R. Ruddell, Eds., pp. 661-688, International Reading Association, Newark, Del, USA, 3rd edition, 1985.

[16] D. E. Rumelhart, "Toward an interactive model of reading," in Theoretical Models and Processes of Reading, R. B. Ruddell, M. R. Ruddell, and H. Singer, Eds., pp. 864-894, International Reading Association, Newark, Del, USA, 4th edition, 1994.

[17] M. Asselin, "Balanced literacy," Teacher Librarian, vol. 27, no. 1, pp. 69-70, 1999.

[18] J. F. Baumann, J. V. Hoffman, J. Moon, and A. M. DuffyHester, "Where are teachers' voices in the phonics/whole language debate? Results from a survey of U.S. elementary classroom teachers," The Reading Teacher, vol. 51, no. 8, pp. 636650, 1998.

[19] K. H. Au, J. H. Caroll, and J. A. Scheu, Balanced Literacy Instruction: A Teacher's Resource Book, Christopher-Gordon, Norwood, Mass, USA, 1997.

[20] M. Pressley, J. Rankin, and L. Yokoi, "A survey of instructional practices of primary teachers nominated as effective in promoting literacy," Elementary School Journal, vol. 96, no. 4, pp. 363-384, 1996.

[21] G. Ivey, J. F. Baumann, and D. Jarrard, "Exploring literacy balance: iterations in a second-grade and a sixth-grade classroom," Reading Research and Instruction, vol. 39, pp. 291-310, 2000. 
[22] B. A. Marinak and W. A. Henk, "Balanced literacy instruction in the elementary school: the West Hanover story," in The Balanced Reading Program, S. M. Blair-Larsen and K. A. Williams, Eds., pp. 136-171, International Reading Association, Newark, Del, USA, 1999.

[23] S. Iversen, "A metacognitive strategy approach to teaching reading: how appropriate and assisted instruction can help all children become readers," Balanced Reading Instruction, vol. 3, no. 1, pp. 12-18, 1996.

[24] D. L. Spiegel, "The perspective of the balanced approach," in The Balanced Reading Program, S. M. Blair-Larsen and K. A. Williams, Eds., pp. 8-23, International Reading Association, Newark, Del, USA, 1999.

[25] C. Bitter, J. O’Day, P. Gubbins, and M. Socias, "What works to improve student literacy achievement? An examination of instructional practices in a balanced literacy approach," Journal of Education for Students Placed at Risk, vol. 14, pp. 17-44, 2009.

[26] M. L. Queenan, "Widening the circle for literacy in an accountability culture," in Proceedings of the Annual Meeting of the Literacy Research Association Conference, Jacksonville, Fla, USA, December 2011.

[27] D. Willows, "The balanced literacy diet," School Administrator, vol. 59, pp. 30-33, 2002.

[28] M. Pressley, A. Roehrig, K. Bogner, L. M. Raphael, and S. Dolezal, "Balanced literacy instruction," Focus on Exceptional Children, vol. 34, pp. 1-14, 2002.

[29] J. Stallings and H.J. Frieberg, "Observation for the improvement of teaching," in Effective Teaching: Current Research, $\mathrm{H}$. C. Hersholt and H. J. Walberg, Eds., pp. 107-133, McCutchan, Berkeley, Calif, USA, 1991.

[30] J. B. Ayers, "Consistency of teacher behavior across time," Education, vol. 103, pp. 375-377, 1983.

[31] N. Tollefson, S. Lee, and L. Webber, The Consistency of Systematic Classroom Observations in Urban Schools, Ewing Marion Kauffman Foundation, Kansas City, Mo, USA, 2001, ERIC Document Reproduction Service No. ED 457155.

[32] S. B. Merriam, Qualitative Research: A Guide to Design and Implementation, Jossey Bass, San Francisco, Calif, USA, 2009.

[33] G. Tompkins, Literacy for the 21st Century: A Balanced Approach, Prentice-Hall, Englewood Cliffs, NJ, USA, 1997.

[34] National Reading Panel, Report of the National Reading Panel: Reports of the Subgroups, National Institute of Child Health and Human Development Clearinghouse, Washington, DC, USA, 2000.

[35] T. Shanahan, "How to improve reading achievement," in Proceedings of the Lexile National Reading Conference, 2005, http://www.shanahanonliteracy.com.

[36] N. K. Duke, P. D. Pearson, S. L. Strachan, and A. K. Billman, "Essential elements of fostering and teaching reading comprehension," in What Research Has to Say About Reading Instruction, S. J. Samuels and A. E. Farstrup, Eds., pp. 94-114, 2011.

[37] National Writing Project, 2011, http://www.nwp.org/cs/public/print/doc/about.csp.

[38] T. V. Rasinski and S.J. Samuels, "Reading fluency: what it is and what it is not," in What Research Has to Say About Reading Instruction, S. J. Samuels and A. E. Farstrup, Eds., pp. 94-114, 2011.

[39] P. Freebody and R. C. Anderson, "Effects of vocabulary difficulty, text cohesion, and schema availability on reading comprehension," Reading Research Quarterly, vol. 18, no. 3, pp. 277-294, 1983.
[40] M. Pressley, L. Raphael, J. D. Gallagher, and J. DiBella, "Providence-St. Mel School: how a school that works for African American students works," Journal of Educational Psychology, vol. 96, no. 2, pp. 216-235, 2004.

[41] R. Wharton-McDonald, M. Pressley, J. Rankin, J. Mistretta, L. Yokoi, and S. Ettenberger, "Effective primary-grades literacy instruction=Balanced literacy instruction," The Reading Teacher, vol. 50, no. 6, pp. 518-521, 1997.

[42] J. Mosenthal, M. Lipson, S. Torncello, B. Russ, and J. Mekkelsen, "Contexts and practices of six schools successful in obtaining reading achievement," Elementary School Journal, vol. 104, no. 5, pp. 343-367, 2004.

[43] E. A. Cheesman, J. M. McGuire, D. Shankweiler, and M. Coyne, "First-year teacher knowledge of phonemic awareness and its instruction," Teacher Education and Special Education, vol. 32, no. 3, pp. 270-289, 2009.

[44] C. Bos, N. Mather, S. Dickson, B. Podhajski, and D. Chard, "Perceptions and knowledge of preservice and inservice educators about early reading instruction," Annals of Dyslexia, vol. 51, pp. 97-120, 2001.

[45] L. C. Moats and B. R. Foorman, "Measuring teachers' content knowledge of language and reading," Annals of Dyslexia, vol. 53, pp. 23-45, 2003.

[46] A. E. Cunningham, K. E. Perry, K. E. Stanovich, and P. J. Stanovich, "Disciplinary knowledge of K-3 teachers and their knowledge calibration in the domain of early literacy," Annals of Dyslexia, vol. 54, no. 1, pp. 139-167, 2004.

[47] N. Mather, C. Bos, and N. Babur, "Perceptions and knowledge of preservice and inservice teachers about early literacy instruction," Journal of Learning Disabilities, vol. 34, no. 5, pp. 472-482, 2001.

[48] M. Haynes, "From state policy to classroom practice: improving literacy instruction for all students," The NASBE State Adolescent Literacy Network, National Association of State Boards of Education, Alexandria, VA, USA, 2007.

[49] N. J. Mooney and A.T. Mauscbach, Align the Design: A Blueprint for School Improvement, Association for Supervision and Curriculum Development, Alexandria, VA, USA, 2008.

[50] A. A. Glatthorn and J.M.S. Jailall, The Principal as Curriculum Leader: Shaping What is Taught and Tested, Corwin, Thousand Oaks, Calif, USA, 2009.

[51] K. Zeichner and J. Gore, “Teacher socialization," in Handbook of Research on Teacher Education, W. R. Houston, M. Haberman, and J. Sikula, Eds., pp. 329-348, Macmillan, New York, NY, USA, 1990. 


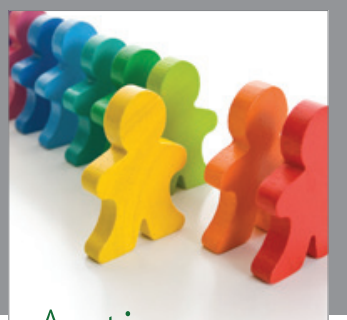

Autism

Research and Treatment
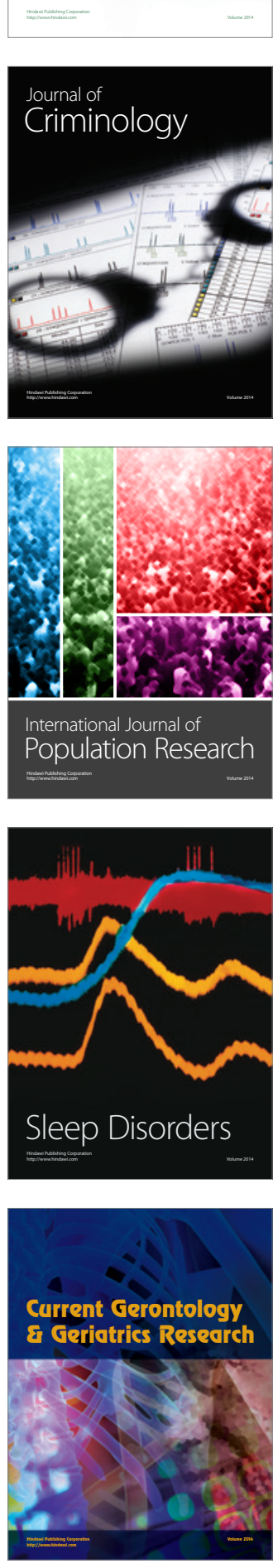
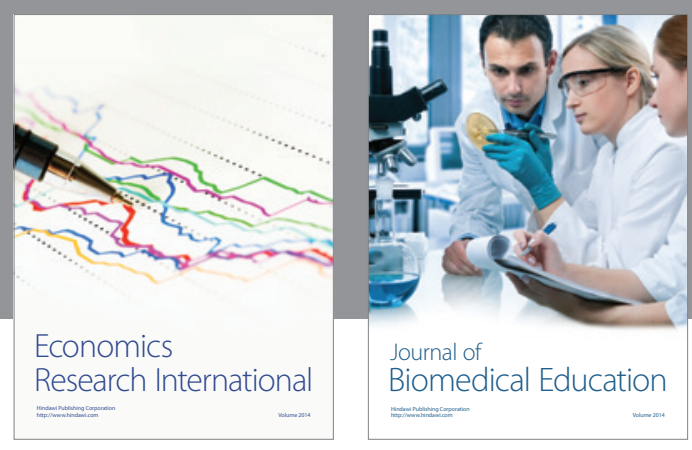

Journal of

Biomedical Education

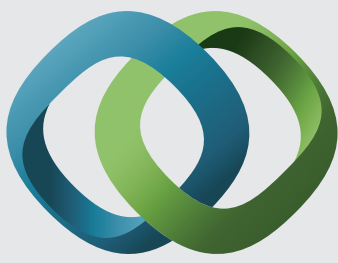

\section{Hindawi}

Submit your manuscripts at

http://www.hindawi.com
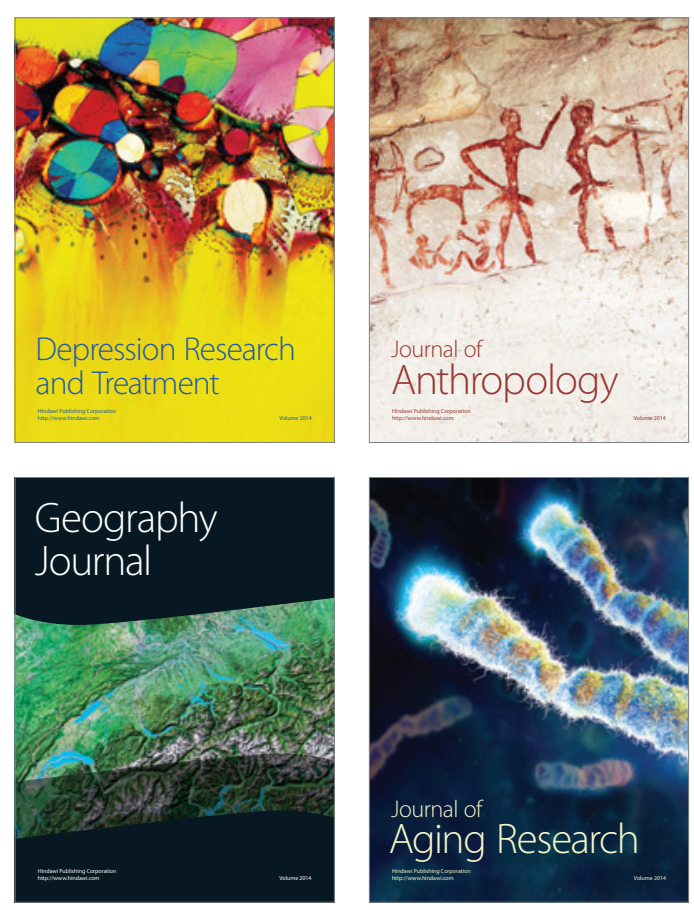

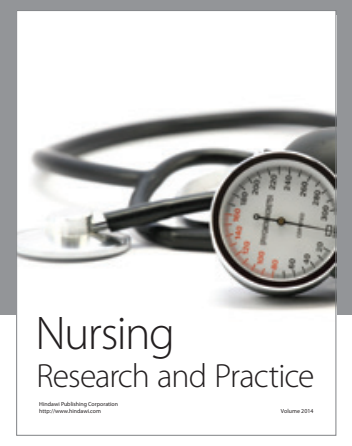

Nursing

Research and Practice

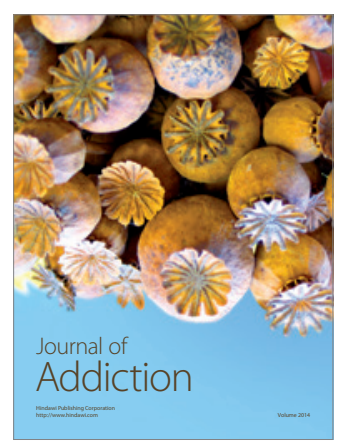

Child Development

Research

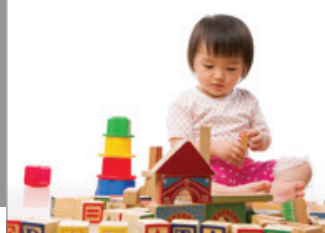

迥
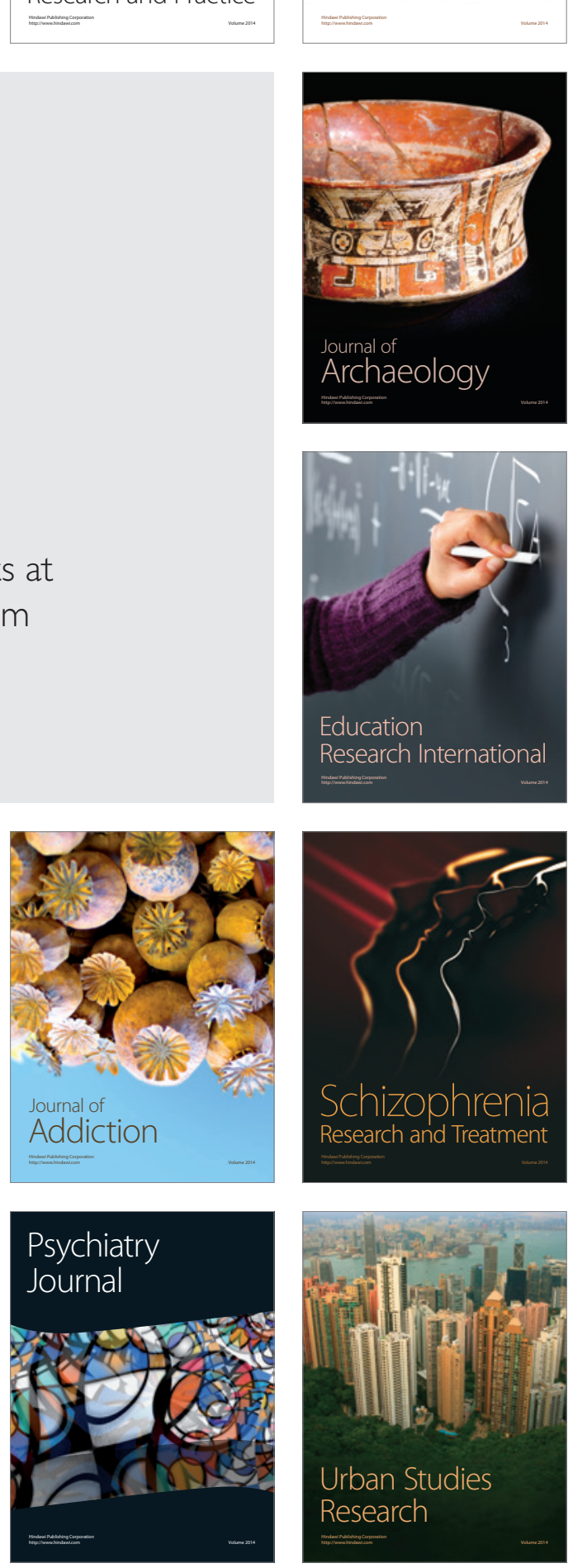